\title{
Synergistic Effect of Iodide Ion and Methyl Violet on the Corrosion Inhibition of Carbon Steel in Phosphoric Acid
}

\author{
Hui Liu, Yan-Ju Yang, Lin Wang ${ }^{*}$, Si-Min Ma, Xiao-Yan Peng, Dong-Mei Lu*, Teng Zhao, \\ Zhong Wang
}

School of Chemical Science and Technology, Key Laboratory of Medicinal Chemistry for Nature Resource, Ministry of Education, Yunnan University, Kunming, Yunnan, 650091, P. R. China *E-mail: wanglin@ynu.edu.cn (LinWang); wanglin2812@163.com

doi: $10.20964 / 2018.11 .28$

Received: 18 June 2018 / Accepted: 22 August 2018 / Published: 1 October 2018

The corrosion inhibition effects of iodide ion and its synergistic effect with methyl violet (MV) on carbon steel in $1.0 \mathrm{~mol} / \mathrm{L}$ phosphoric acid solution have been investigated using potentiodynamic polarization, electrochemical impedance spectroscopy and weight loss measurements. The results show that there is an excellent synergistic effect between iodide ion and MV for carbon steel corrosion inhibition in $1.0 \mathrm{~mol} / \mathrm{L} \mathrm{H}_{3} \mathrm{PO}_{4}$. The electrochemical studies reveal that single iodide ion or combination of iodide ion and $\mathrm{MV}$ acts as a mixed-type inhibitor and the corrosion reaction is controlled by charge transfer process. Adsorption of iodide ion on the steel surface obeys Langmuir adsorption isotherm in the absence or presence of MV. The values of $K_{\mathrm{ads}}, \Delta G_{a d s}^{\mathrm{o}}, \Delta H_{a}, \Delta S_{a}$ and $E_{\mathrm{a}}$ were obtained and discussed. The adsorption of inhibitor molecules on the steel surface is a spontaneous process containing a mixed physical and chemical adsorption mechanism.

Keywords: Carbon steel, Corrosion, Phosphoric acid, Iodide ion, Methyl violet, Synergistic inhibition.

\section{$\underline{\text { FULL TEXT }}$}

(C) 2018 The Authors. Published by ESG (www.electrochemsci.org). This article is an open access article distributed under the terms and conditions of the Creative Commons Attribution license (http://creativecommons.org/licenses/by/4.0/). 